\title{
Bright-Field and Fluorescence Microscopic Study of Development of Erysiphe polygoni in Susceptible and Resistant Bigleaf Hydrangea
}

\author{
Yonghao Li, Mark T. Windham, and Robert N. Trigiano, Dept. of Entomology and Plant Pathology, University of \\ Tennessee, Knoxville, TN 37996-4560; Sandra M. Reed, USDA/ARS Floral \& Nursery Plants Research Unit, \\ McMinnville, TN 37110; and James M. Spiers and Timothy A. Rinehart, USDA/ARS Thad Cochran Horticultural \\ Research Laboratory, Poplarville, MS 39470
}

\begin{abstract}
Li, Y. H., Windham, M. T., Trigiano, R. N., Reed, S. M., Spiers, J. M., and Rinehart, T. A. 2009. Bright-field and fluorescence microscopic study of development of Erysiphe polygoni in susceptible and resistant bigleaf hydrangea. Plant Dis. 93:130-134.

Temporal development of Erysiphe polygoni and responses of bigleaf hydrangeas (Hydrangea macrophylla) to the fungal attack were investigated using bright-field and fluorescence microscopy. Conidia germinated $2 \mathrm{~h}$ after inoculation (HAI) and formed primary appressoria at the tip of the primary germ tubes within 4 HAI. Secondary germ tubes were initiated from primary appressoria or other parts of conidia 12 HAI. Hyphae developed through elongation of secondary germ tubes, and paired lateral appressoria were formed along hyphae within 2 days after inoculation (DAI). Conidiophores and conidia were formed 5 DAI. In the susceptible cultivar Nikko Blue and the resistant cultivar Veitchii, the fungus established a parasitic relationship, which was indicated by the formation of haustoria under primary appressoria and development of secondary germ tubes at 1 DAI. A hypersensitive response (HR) and accumulation of callose were detected in both resistant and susceptible cultivars at 3 DAI. Resistance to powdery mildew in Veitchii was evident by manifestation of early accumulation of callose, relatively high percentage of necrotic infected cells, and restricted colony development compared to the susceptible cultivar Nikko Blue. Restricting hyphal growth and sporulation by early response of callose accumulation and HR are important resistance mechanisms that could be used in screening hydrangeas for resistance to powdery mildew.
\end{abstract}

Many plant pathogenic fungi penetrate host cells by means of enzymatic and/or physical mechanisms. At the same time, a series of defense responses is induced in host plants when a pathogen is recognized (13). Powdery mildew fungi develop on surfaces of hosts except for haustoria that are formed inside host cells and absorb water and nutrients. Therefore, infection structure formation and fungal development can be studied by microscopic techniques. Fungal development and host responses have been documented for many powdery mildew pathosystems. An early response to powdery mildew fungal attacks is formation of papillae by accumulation of callose and/or compounds, such as lignin, on the host cell walls opposite penetration sites $(5,10,34)$. After establishment of a biotrophic relationship, a hypersensitive response (HR), characterized as a rapid death of the attached cells, is another ma-

Corresponding author: M. T. Windham

E-mail: mwindham@utk.edu

Accepted for publication 22 October 2008.

doi:10.1094/PDIS-93-2-0130

This article is in the public domain and not copyrightable. It may be freely reprinted with customary crediting of the source. The American Phytopathological Society, 2009. jor resistance mechanism to restrict fungal development $(4,21,29,33)$.

Powdery mildew, caused by Erysiphe polygoni DC., is a foliar disease of bigleaf hydrangea (Hydrangea macrophylla (Thunb.) Ser.). Plants grown in greenhouses or in shade are particularly susceptible to the disease $(7,35)$. Powdery mildew colonies develop on the upper and lower leaf surfaces and affect inflorescences (35). Fungal colony growth can cause yellow or purple blotches on infected leaves (7). Variation of reaction to E. polygoni among bigleaf hydrangea cultivars has been noted in greenhouses and gardens (7). However, the infection process of the fungus and the nature of defense reactions in host plants are unknown. For developing efficient integrated disease management strategies of powdery mildew for hydrangea, it is essential to understand how the fungus infects plants and how plants respond to fungal attacks. The objectives of this study were to describe the infection process, examine host responses to the fungal attacks, and compare fungal development in susceptible and resistant cultivars of bigleaf hydrangea.

\section{MATERIALS AND METHODS}

Plants and inoculum. Two-year-old bigleaf hydrangea plants of 'Nikko Blue' and 'Veitchii' were potted in 3-gallon con- tainers and grown in a greenhouse under a $50 \%$ shade cloth at the Plant Sciences Unit of the East Tennessee Research \& Education Center of the University of Tennessee at Knoxville. Nikko Blue and Veitchii were reported to be susceptible and resistant to powdery mildew, respectively (7). Powdery mildew inoculum was collected from naturally infected hydrangea plants at the Otis L. Floyd Nursery Research Center, McMinnville, $\mathrm{TN}$ and maintained on Nikko Blue plants grown in a greenhouse at the campus of University of Tennessee at Knoxville.

Inoculation. Healthy hydrangea leaves were collected from the plants of Nikko Blue and washed in running distilled water for $1 \mathrm{~min}$. Leaf disks, $0.9 \mathrm{~cm}$ in diameter, were cut using a cork borer and placed adaxial surface up on two layers of moistened filter paper in 9-cm-diameter petri dishes. Leaf disks were inoculated with $E$. polygoni conidia from diseased hydrangea leaves in a settling tower (20) and incubated at $21 \pm 1{ }^{\circ} \mathrm{C}$ with a continuous photoperiod. Light was provided by four 40 -watt residential fluorescent bulbs from $45 \mathrm{~cm}$ above leaf disks. The spore density on inoculated leaf disks was maintained at 4 to 6 conidia $/ \mathrm{mm}^{2}$ by adjusting the number of air blasts during the inoculation. Conidia per unit area of leaf disks were determined by counting spore numbers on the glass slide placed beside the leaf disks when they were inoculated in the settling tower.

Infection process observation. Leaf disks were sampled at 1, 2, 3, 4, 5, 6, and $12 \mathrm{~h}$ after inoculation (HAI), and at 24-h intervals from 1 to 5 days after inoculation (DAI). Sampled leaf disks were fixed by soaking the disks in a drop of $95 \%$ ethanol in a petri dish for $3 \mathrm{~h}$ and stained with Calcofluor white in $10 \% \mathrm{KOH}$ (Eng Scientific, Inc., Clifton, NJ). Stained disks were mounted on glass slides and examined for the development of infection structures and fungal colonies using an Eclipse 80i fluorescence microscope with UV $2 \mathrm{E} / \mathrm{C}$ filter block (excitation 340 to $380 \mathrm{~nm}$ ) (Nikon Instruments, Melville, NY). Fungal structures fluoresced blue on the black background of the leaf disks. The sizes of hyphae, conidia, and conidiophores were measured using NIS-Elements software (Nikon Instruments).

Haustorium and dead cell observation. Fungal haustorium formation and 
host cell death were examined after staining leaf disks with trypan blue as described by Sillero and Rubiales (31). Inoculated leaf disks were sampled in a series of time points as described above and placed on two layers of filter paper moistened with acetic acid:ethanol (1:3, vol/vol) fixation solution for $30 \mathrm{~min}$. Fixed disks were stained with $0.05 \%$ trypan blue in lactophenol:ethanol $(1: 2, \mathrm{vol} / \mathrm{vol})$ in an autoclave at $121^{\circ} \mathrm{C}$ for $3 \mathrm{~min}$. Cooled stained leaf disks were cleared on filter papers soaked with saturated chloral hydrate $(5: 2$, $\mathrm{wt} / \mathrm{vol}$ ) for $48 \mathrm{~h}$ at room temperature by replacing filter papers and chloral hydrate at $24 \mathrm{~h}$. The disks were mounted in $50 \%$ glycerol, and coverslips were sealed on glass slides with Permount (Fishers Scientific, Fair Lawn, NJ). Dead cells were assessed by observing 100 to 130 infected cells with haustoria for each leaf disk using a compound microscope with brightfield microscopy. Percent dead cells was defined as the percentage of infected epidermal cells with more than $50 \%$ of the cell wall heavily stained by trypan blue at 5 DAI. Experiments were conducted as a randomized complete block design. The inoculation in the settling tower was a blocking factor, and the experiment was repeated two times. Data were analyzed using a general linear regression procedure, and means were compared using the least square differences of SAS software (Version 9.1, SAS Institute Inc., Cary, NC).

Callose observation. Inoculated leaf disks were sampled and fixed on two layers of filter paper soaked with acetic acid:ethanol solution $(1: 3, \mathrm{vol} / \mathrm{vol})$ in petri dishes for $48 \mathrm{~h}$. Filter papers and the fixation solution were changed after $24 \mathrm{~h}$ during the fixation process. Disks were soaked in a drop of distilled water in a petri dish for $24 \mathrm{~h}$, stained with $0.01 \%$ aniline blue in $0.05 \mathrm{M} \mathrm{K}_{2} \mathrm{HPO}_{4}, \mathrm{pH} 9.5$, for $2 \mathrm{~h}$, soaked in water for $30 \mathrm{~min}$, and then mounted in $50 \%$ glycerol on glass slides (27). Coverslips were sealed onto slides with Permount and examined using the fluorescence microscope with a BV-2A filter block (excitation 400 to $440 \mathrm{~nm}$ ) and differential interference contrast (DIC) microscopy.

Colony development. Inoculated leaf disks were sampled at $6 \mathrm{DAI}$ and stained using a method described by Schiffer et al.
(30). Sampled disks were placed on two layers of filter paper saturated with a solution of $0.15 \%$ trichloroacetic acid in chloroform:ethanol $(1: 4, \mathrm{vol} / \mathrm{vol})$ in petri dishes at room temperature $\left(20 \pm 1{ }^{\circ} \mathrm{C}\right)$. Filter papers within the petri dishes were changed at $24 \mathrm{~h}$ during a 48 -h period. Cleared leaf disks were stained with $0.6 \%$ Coomassie brilliant blue R-250 in 10\% trichloroacetic acid for $30 \mathrm{~s}$ and washed with 5 drops of distilled water. After disks were mounted in $50 \%$ glycerol on glass slides, development of hyphae, branched hyphae, and conidia was observed using a compound microscope with bright-field. Necrotic host cells or lesions were observed on fresh leaf disks using a stereo microscope, and images were acquired using a Sony digital still camera MVC-CD500 (Sony Electronics Inc., Park Ridge, NJ).

\section{RESULTS}

Infection process. The morphology and infection sequence of $E$. polygoni on leaf disks of Nikko Blue were observed using fluorescence microscopy. Conidia of $E$. polygoni were ovoid-ellipsoid in shape, $29.4 \mu \mathrm{m}(\mathrm{SD}=4.4 \mu \mathrm{m}, n=27)$ in length
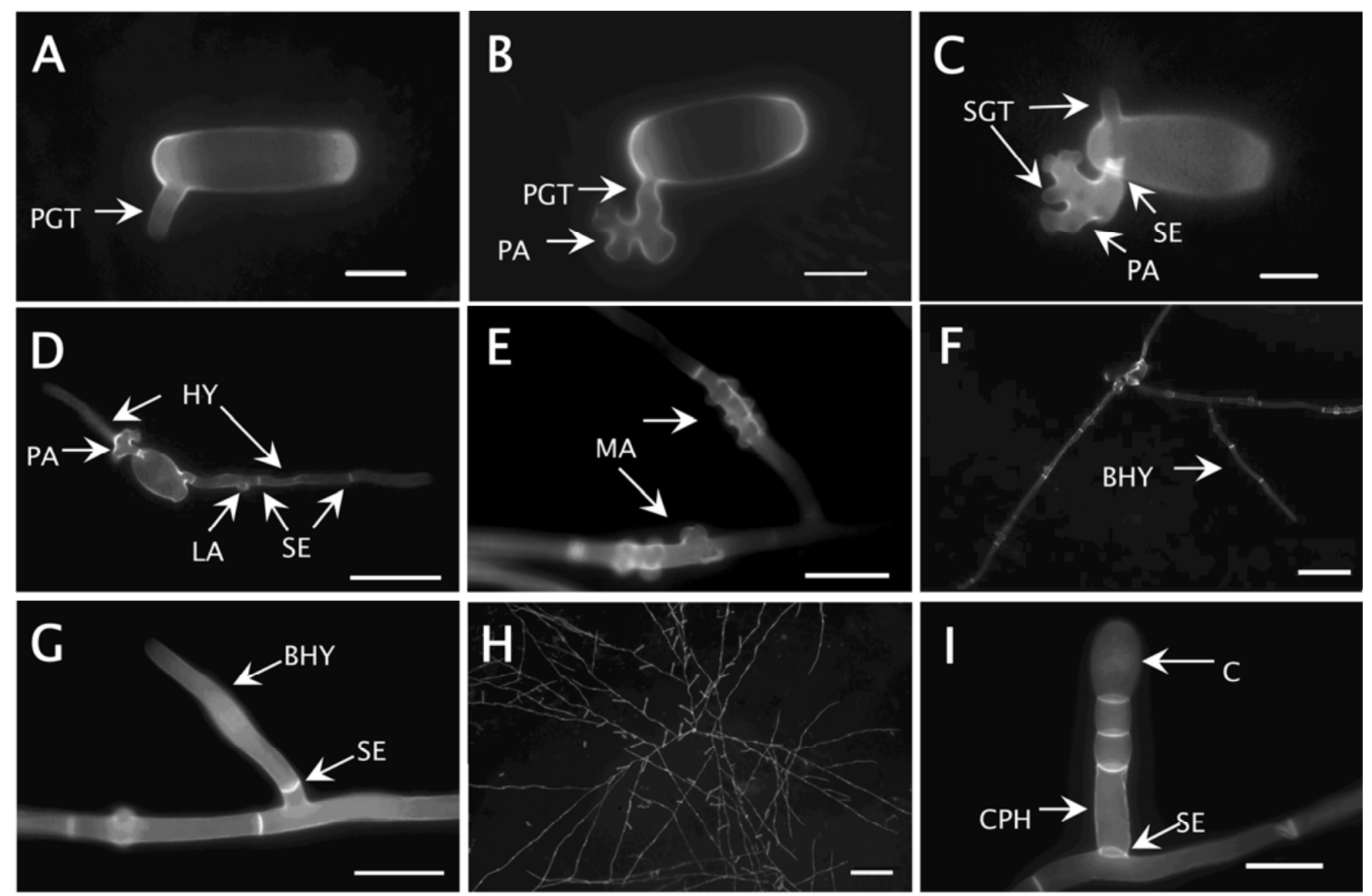

Fig. 1. Light micrographs of development of Erysiphe polygoni on hydrangea leaf disks stained with Calcofluor and observed under a fluorescence microscope using UV 2E/C filter block (excitation 340-380 nm). A, Germinating conidium with primary germ tube (PGT) at $2 \mathrm{~h}$ after inoculation (HAI), scale bar $=10 \mu \mathrm{m} ; \mathbf{B}$, formation of primary appressorium (PA) at the tip of primary germ tube $4 \mathrm{HAI}$, scale bar $=10 \mu \mathrm{m}$; $\mathbf{C}$, secondary germ tubes (SGT) initiated from a conidium and primary appressorium with a septa (SE) separating the conidium and primary appressorium $12 \mathrm{HAI}$, scale bar $=10 \mu \mathrm{m}$; D, growth of secondary germ tubes as hyphae (HY) with septa and lateral appressoria (LA) 1 day after inoculation (DAI), scale bar $=40 \mu \mathrm{m}$; E, multiple appressoria (MA) between two septa, scale bar $=20 \mu \mathrm{m} ; \mathbf{F}$, more than one hypha growing from a conidium and branched hypha (BHY) 3 DAI, scale bar $=50 \mu \mathrm{m}$; G, a branched hypha with a septa near the hypha, scale bar $=20 \mu \mathrm{m} ; \mathbf{H}$, a colony developed from a germinated conidium, note sporulation, scale bar $=200 \mu \mathrm{m}$; and $\mathbf{I}$, close-up of a conidium $(\mathrm{C})$ at the top of a conidiophore $(\mathrm{CPH})$ with septa, scale bar $=50 \mu \mathrm{m}$. 
and $8.9 \mu \mathrm{m}(\mathrm{SD}=0.9 \mu \mathrm{m}, n=26)$ in width. Germinating conidia initiated primary germ tubes 2 HAI (Fig. 1A). Multilobed primary appressoria developed at the tip of primary germ tubes 4 HAI (Fig. 1B). By 12 HAI, secondary germ tubes were initiated from primary appressoria and the other parts of the conidia (Fig. 1C). Secondary germ tubes continued to grow as hyphae with paired lateral appressoria (Fig. 1D). Multiappressoria were occasionally observed from a hyphal cell, although a single pair of appressoria was common (Fig. 1E). Among the two or three hyphae developed from a germinated conidium, at least one hypha originated from the primary appressorium (Fig. 1D and F). By 3 DAI, branched hyphae developed from elongated hyphae (Fig. 1F and G). Average width of branched hyphae was $4.1 \mu \mathrm{m}$ (SD $=0.5 \mu \mathrm{m}, n=34)$. Branched hyphae developed at an acute angle without the septa delimiting them from original hyphae (Fig. 1G). Hyphae maintained directional growth from the point of their initiation to form colonies. Conidiophores and conidia were observed on fungal colonies 5 DAI (Fig. 1H). Conidiophores that were perpendicular to hyphae were delimited by a septum at the bottom of the base cell followed by two or three straight cells (Fig. 1I). The width of conidiophores was 7.1 $\mu \mathrm{m}(\mathrm{SD}=0.6 \mu \mathrm{m}, n=26)$, which was wider than that of branched hyphae.

Cellular responses to the fungal attack. To visualize the development of haustoria within epidermal cells and HR, inoculated leaf disks were stained with trypan blue and examined using brightfield microscopy. Haustoria were observed in epidermal cells under primary appressoria in both Nikko Blue and Veitchii 1 DAI (Fig. 2A and B). By 3 DAI, dead cells were not detected in the susceptible cultivar Nikko Blue (Fig. 2C), whereas heavily stained cell walls, indicating cell death, were observed in resistant Veitchii at 3 DAI (Fig. 2D). By 5 DAI, dead cells were observed in both Nikko Blue (Fig. 2E) and Veitchii (Fig. 2F). In general, the number of dead cells was greater on Nikko Blue than on Veitchii, which was associated with more infected cells in plants of Nikko Blue. However, the mean of percent dead cells in infected epidermal cells was significantly different between two cultivars $(P=0.0040)$ at 5 DAI. The percentage of dead cells for Veitchii $(65.6 \%)$ was three times greater than that for Nikko Blue $(21.2 \%)$.

Callose accumulation. To examine the accumulation of callose responding to the fungal attacks, leaf disks were stained with aniline blue and examined using epifluorescence and DIC microscopy. By 1 DAI, callose accumulation was rarely detected under the primary appressoria on the susceptible cultivar Nikko Blue (Fig. 3A), but callose accumulation was commonly observed under the infection sites in the re- sistant cultivar Veitchii (Fig. 3B). By 3 DAI, callose accumulated under primary and lateral appressoria in leaf disks of Nikko Blue (Fig. 3C) and Veitchii (Fig. 3D).

Colony development. Radial fungal colonies with plentiful branched hyphae developed from germinated conidia and sporulation were observed on susceptible Nikko Blue 6 DAI (Fig. 4A). However, on the resistant cultivar Veitchii, branched hyphae were not, or rarely, detected, although hyphae developed from germinated conidia (Fig. 4B). By 10 DAI, necrotic cells were detected in both susceptible Nikko Blue and resistant Veitchii, but sporulation was observed only on the susceptible cultivar (Fig. 5A), not on the resistant cultivar (Fig. 5B).

\section{DISCUSSION}

In this study, epifluorescence and brightfield microscopy were employed to examine the development of E. polygoni on detached leaf disks of bigleaf hydrangeas. To our knowledge, this is the first time that details of the infection process of E. polygoni have been described and the first attempt to compare responses to the infection of the fungus in resistant and susceptible bigleaf hydrangea cultivars. Restriction of colony development by early accumulation of callose and HR in Veitchii provide important information for breeding of resistant cultivars and management of powdery mildew in bigleaf hydrangeas.

Conidia of E. polygoni initiated primary germ tubes $2 \mathrm{HAI}$, and primary appressoria formed at the end of primary germ tubes $4 \mathrm{HAI}$, which is similar to the reports for other powdery mildew fungi $(3,12,24,25,32)$. However, patterns of infection structure formation differed from reports of some pathosystems of powdery mildew. Conidia of Erysiphe pulchra (Cooke \& Peck) U. Braun \& S. Takam., causal agent of powdery mildew of dogwood, initiated two to three primary germ tubes from a conidium, and the primary appressorium formed at the end of only one of the primary germ tubes. Secondary germ tubes were initiated from primary appressoria (20). In contrast, the primary germ tubes of Blumeria graminis (DC.) E.O. Speer, the causal agent of wheat and barley powdery mildew, did not form appressoria, but the secondary germ tubes formed hook-shaped appressoria, and hyphae developed from appressoria $(2,11,16)$. In the present study, conidia of E. polygoni initiated only one primary germ tube, the appressorial germ tube, and two to three secondary germ tubes emerged from primary appressoria and conidia. The pattern of primary appressorium formation, or the appressorial germ tube initiation, was reported to be a distinguishing feature in powdery mildew fungi $(16,20)$.

Powdery mildew fungi are obligate biotrophs that have mycelial growth occur- ring only on the plant surfaces. Hypha development by elongation of the secondary germ tube occurs after haustorium formation in epidermal cells under primary appressoria. Formation of functional haustoria or development of hyphae from conidia was considered as the establishment of a parasite relationship for powdery mildew fungi $(13,15,20)$. In the present study, the formation of haustoria and hyphal growth in susceptible and resistant cultivars at 1 DAI indicated that $E$. polygoni can establish a parasite relationship with host plants regardless of levels of resistance. In some observations of the present study, multiple appressoria were associated with a hyphal cell, although a single pair of appressoria was common. The frequency of multiple appressoria of $\mathrm{Un}$ cinula necator (Schw.) Burr. was associated with increased resistance levels to powdery mildew in grapevine cultivars (8), leaf ages (18), and berry ages (9). These results suggested that multiple appressorium formation might be due to the need for additional functional haustoria to support fungal growth.

Physical reinforcement of cell walls through the formation of papillae at penetration sites is widely recognized as an early response in host plants to microbial attack $(10,14,19,23)$. A common compound of papillae is callose $(\beta-1,3$-glucan) (13), but papillae formation was reported to be independent of callose deposition in the interaction of Arabidopsis and Erysiphe cichoracearum DC. (23). Deposition of papillae is detectable under penetration sites in both compatible and incompatible plant-microbe interactions $(1,13,37)$. However, accumulation of callose was earlier in resistant cultivars than in susceptible cultivars $(13,17,19)$. In the present study, callose accumulation was detected under the primary and secondary appressoria and parts of cell walls in both resistant and susceptible bigleaf hydrangea cultivars. However, callose accumulation under the primary appressorium was observed in the resistant cultivar at 1 DAI, which was 2 days earlier than in the susceptible cultivar. The present result suggests that early accumulation of callose is one of the resistance mechanisms to powdery mildew in hydrangea. Besides the accumulation of callose, papillae also have been reported to be sites for the accumulation of antimicrobial or microbial-static biochemical compounds including peroxidases, $\mathrm{H}_{2} \mathrm{O}_{2}$, phenolic polymines, proteins, and glycoproteins $(6,10,28,37)$. Phenolics were reported to be associated with collapse of fungal haustoria (36) or antifungal activity (22). Earlier response to fungal penetration in the resistant cultivar may slow the penetration process and/or the formation of haustoria due to epidermal cell wall toughening or antimicrobial products accumulation. 


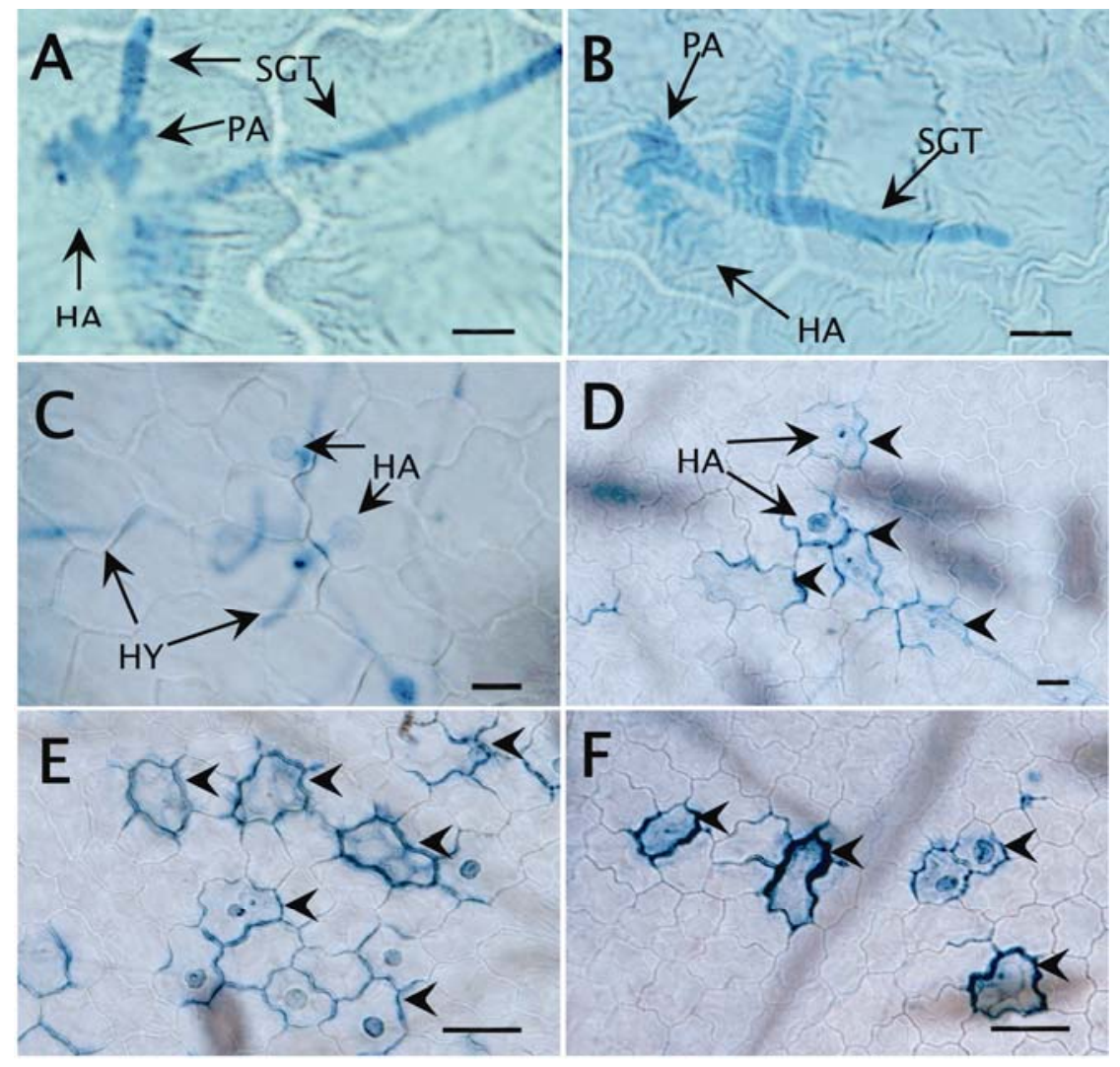

Fig. 2. Light micrographs of haustoria of Erysiphe polygoni in epidermis and cell death responding to the attack in leaf disks that were stained with trypan blue and cleared with chloral hydrate. Germinated conidia with primary appressoria (PA) and secondary germ tubes (SGT) on leaf surface and haustoria (HA) in epidermal cells of A, 'Nikko Blue' and B, 'Veitchii' at $24 \mathrm{~h}$ after inoculation. Haustoria under appressoria along hyphae (HY) in C, Nikko Blue without dead cells and D, Veitchii with dead cell walls (arrowhead) characterized as heavily stained cell walls at 3 days after inoculation (DAI). Haustoria in epidermis with dead cell walls of $\mathbf{E}$, Nikko Blue and $\mathbf{F}$, Veitchii at 5 DAI.

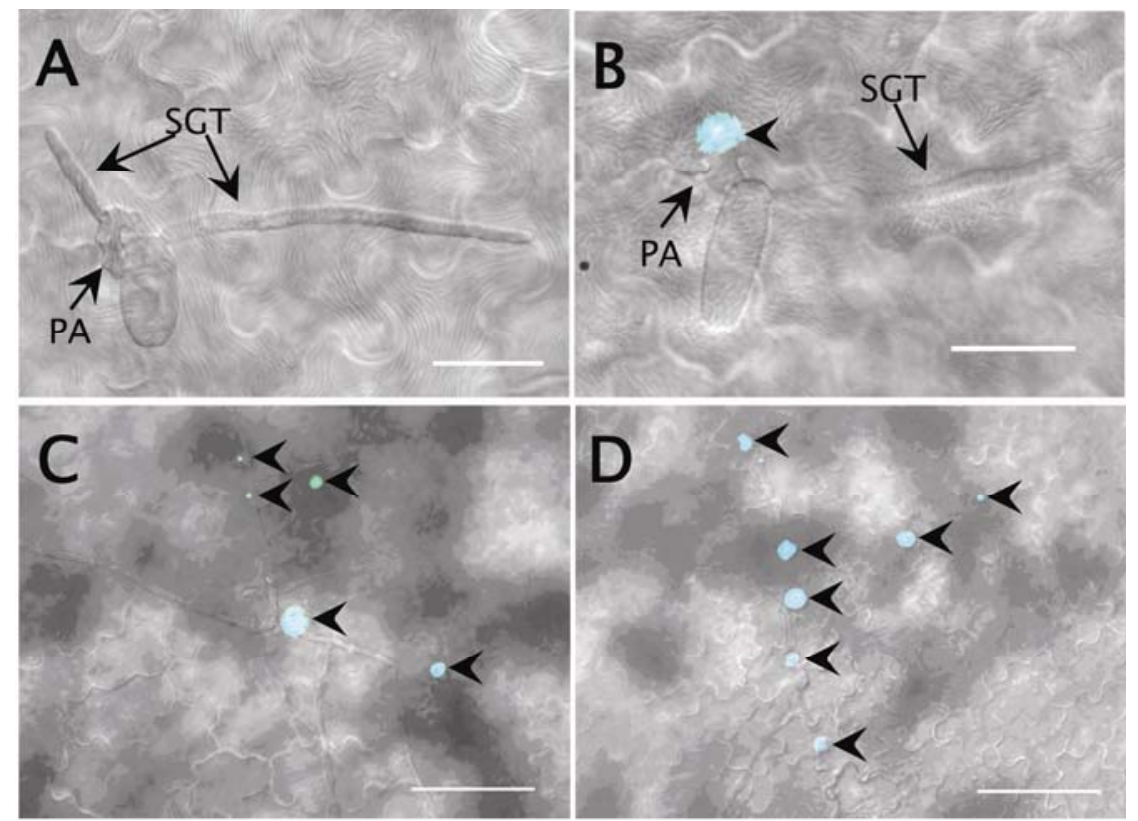

Fig. 3. Micrographs of callose accumulation under appressoria and epidermal cell walls observed using fluorescence and differential interference contrast (DIC) microscopy. Germinated conidia with primary appressoria (PA) and secondary germ tubes (SGT) on leaf disks of A, 'Nikko Blue' without callose accumulation and B, 'Veitchii' with callose accumulation (arrowhead) in the merged DIC and fluorescence images with green and blue component at 1 day after inoculation (DAI), bars $=20 \mu \mathrm{m}$. Callose accumulation under primary and lateral appressoria on leaf disks of C, Nikko Blue and D, Veitchii in merged DIC and fluorescence images with green and blue component 3 DAI, bars $=50 \mu \mathrm{m}$.
As a posthaustorial resistance mechanism, HR is considered to act against biotrophic pathogens by restricting access to water and nutrients from host cells (10), preventing fungal development and restricting fungal growth $(4,21,29,31,33)$. Higher levels of resistance to powdery mildew were characterized as earlier HR $(17,26)$ or higher frequency of HR in epidermal cells with primary and secondary haustoria $(12,26)$. In the present study, HR was 1 to 2 days earlier, colony development was restricted, and sporulation was
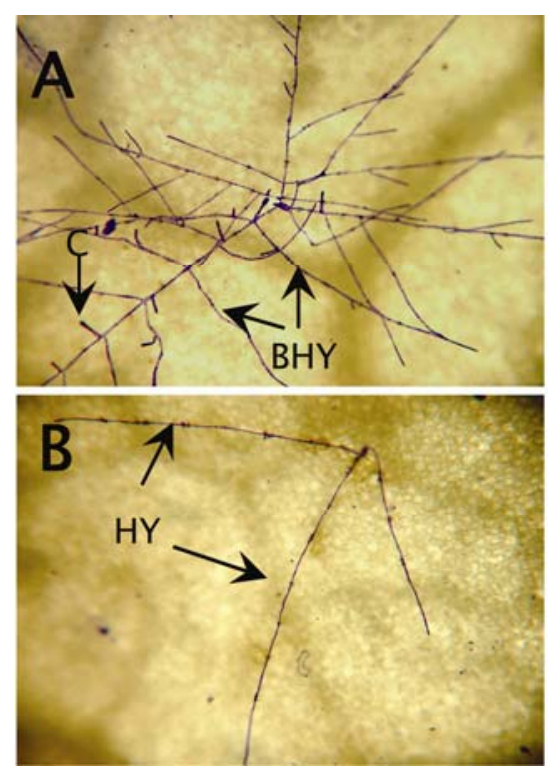

Fig. 4. Micrographs of colony development with hyphae (HY), branched hyphae (BHY), and conidia (C) production on leaf disks A, 'Nikko Blue' and $\mathbf{B}$, 'Veitchii' at 6 days after inoculation. Leaf disks were stained with $0.6 \%$ Coomassie brilliant blue.

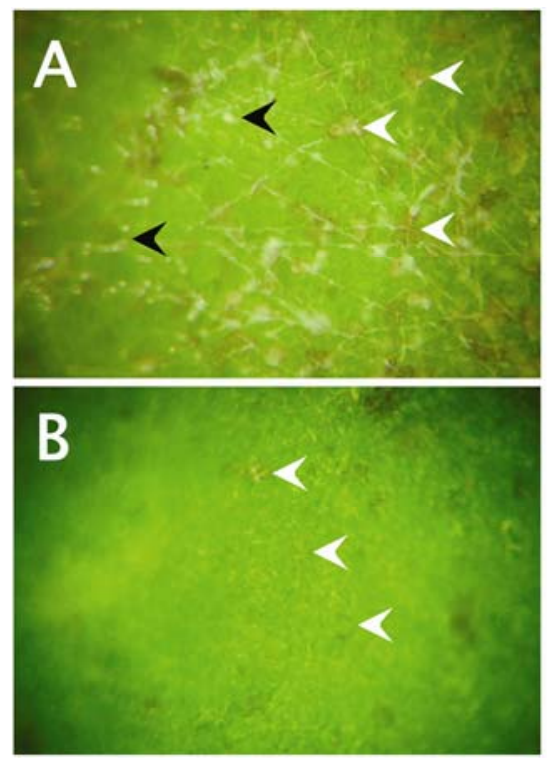

Fig. 5. Colony development on leaf disks of $\mathbf{A}$, 'Nikko Blue' with necrotic cells (white arrowhead) and fungal sporulation (black arrowhead) and $\mathbf{B}$, 'Veitchii' with necrotic cells, but no fungal sporulation at 10 days after inoculation. 
delayed on the resistant cultivar compared to the susceptible cultivar. Additionally, percentages of dead infected cells were higher in the resistant cultivar than in the susceptible cultivar. These results suggested that HR and restriction of fungal growth are important resistance components that could be used to screen hydrangea plants for resistance to powdery mildew.

In the present study, we documented the infection structure formation and colony development of E. polygoni in susceptible and resistant bigleaf hydrangea cultivars. Haustoria formed in epidermal cells are important fungal structures for powdery mildew fungi since hyphae growth and colony development on host surfaces rely on water and nutrient from host epidermal cells. Further studies are needed to understand early responses of resistant hydrangea in the aspects of histology, ultrastructure, biochemistry, and associated genes.

\section{ACKNOWLEDGMENTS}

This study was supported by funding from USDA-ARS (58-6404-2-0057).

\section{LITERATURE CITED}

1. Adam, L., and Somerville, S. C. 1996. Genetic characterization of five powdery mildew disease resistance loci in Arabidopsis thaliana. Plant J. 9:341-356.

2. Aist, J. R., and Bushnell, W. R. 1991. Invasion of plants by powdery mildew fungi, and cellular mechanisms of resistance. Pages 321-345 in: The Fungal Spore and Disease Initiation in Plants and Animals. T. C. Garry and C. H. Harvey, eds. Plenum Press, New York.

3. Celio, G. J., and Hausbeck, M. K. 1998. Conidial germination, infection structure formation, and early colony development of powdery mildew on poinsettia. Phytopathology 88:105113.

4. Cohen, Y., and Eyal, H. 1988. Epifluorescence microscopy of Spherotheca fuliginea race 2 on susceptible and resistant genotypes of Cucumis melo. Phytopathology 78:144-148.

5. Cohen, Y., Eyal, H., and Hanania, J. 1990. Ultrastructure, autofluorescence, callose deposition and lignification in susceptible and resistant muskmelon leaves infected with the powdery mildew fungus Sphaerotheca fuliginea. Physiol. Mol. Plant Pathol. 36:191-204.

6. Collinge, D. B., Gregersen, P. L., and ThordalChristensen, H. 2002. The nature and role of defense response genes in cereals. Pages 146160 in: The Powdery Mildews: A Comprehensive Treatise. R. R. Bélanger, W. R. Bushnell, A. J. Dik, and T. L.W. Carver, eds. American Phytopathological Society, St Paul, MN.

7. Dirr, M. 2004. Hydrangeas for American Gardens. Timber Press, Portland, OR.

8. Doster, M. A., and Schnathorst, W. C. 1985. Effects of leaf maturity and cultivar resistance on development of the powdery mildew fungus on grapevines. Phytopathology 75:318-321.

9. Ficke, A., Gadoury, D. M., Seem, R. C., and Dry, I. B. 2003. Effects of ontogenic resistance upon establishment and growth of Uncinula necator on grape berries. Phytopathology 93:556-563.

10. Glozebrook, J. 2005. Contrasting mechanisms of defense against biotrophic and necrotrophic pathogens. Annu. Rev. Phytopathol. 43:205-227.

11. Green, J. R., Carver, T. L. W., and Gurr, S. J. 2002. The formation and function of infection and feeding structures. Pages 66-82 in: The Powdery Mildews: A Comprehensive Treatise. R. R. Belanger, W. R. Bushnell, A. J. Dik, and T. L. W. Carver, eds. American Phytopathological Society, St. Paul, MN.

12. Huang, C. C., Groot, T., Meijer-Dekens, F., Niks, R. E., and Lindhout, P. 1998. The resistance to powdery mildew (Oidium lycopersicum) in Lycopersicon species is mainly associated with hypersensitive response. Eur. J. Plant Pathol. 104:399-407.

13. Hückelhoven, R. 2007. Cell wall-associated mechanisms of disease resistance and susceptibility. Annu. Rev. Phytopathol. 45:101-127.

14. Jacobs, A. K., Lipka, V., Burton, R. A., Panstruga, R., Strizhov, N., Schulze-Lefert, P., and Fincher, G. B. 2003. An Arabidopsis callose synthase, GSL5, is required for wound and papillary callose formation. Plant Cell 15:2503-2513.

15. Koh, S., André, A., Edwards, H., Ehrhardt, D., and Somerville, S. 2005. Arabidopsis thaliana subcellular responses to compatible Erysiphe cichoracearum infections. Plant J. 44:516-529.

16. Kunoh, H., Itoh, O., Kohno, M., and Ishizaki, H. 1979. Are primary germ tubes of conidia unique to Erysiphe graminis? Ann. Phytopathol. Soc. Jpn. 45:675-682.

17. Kuzuya, M., Yashiro, K., Tomita, K., and Ezura, H. 2006. Powdery mildew (Podosphaera xanthii) resistance in melon is categorized into two types based on inhibition of the infection process. J. Exp. Bot. 57:2093-2100.

18. Leinhos, G. M. E., Gold, R. E., and Düggelin, M. 1997. Development and morphology of Uncinula necator following treatment with the fungicides kresoxim-methyl and penconazole. Mycol. Res. 101:1033-1040.

19. Li, C., Bonnema, G., Che, D., Dong, L., Lindhout, P., Visser, R., and Bai, Y. 2007. Biochemical and molecular mechanisms involved in monogenic resistance responses to tomato powdery mildew. Mol. Plant-Microbe Interact. 20:1161-1172.

20. Li, Y. H., Windham, M. T., Trigiano, R. N., Fare, D. C., Spiers, J. M., and Copes, W. E. 2005. Spore germination, infection structure formation, and colony development of Erysiphe pulchra on dogwood leaves and glass slides. Plant Dis. 89:1301-1304.

21. Li, Y. H., Windham, M. T., Trigiano, R. N., Fare, D. C., Spiers, J. M., and Copes, W. E. 2006. Development of Erysiphe pulchra, the causal agent of powdery mildew, on leaf disks of susceptible and resistant flowering dogwood (Cornus florida). Can. J. Plant Pathol. 28:7176.

22. McNally, D. J., Labbé, C., and Bélanger, R. R. 2001. An improved methodology for characterizing novel phytoalexins from Cucumis sativus L. (Abstr.) Phytopathology 91:S196.

23. Nishimura, M. T., Stein, M., Hou, B. H., Vogel, J. P., Edwards, H., and Somerville, S. C. 2003. Loss of a callose synthase results in salicylic acid-dependent disease resistance. Science 301:969-972.

24. Pérez-Garcia, A., Olalla, L., Rivera, E., Del
Pino, D., Cánovas, I., De Vicente, A., and Torés, J. A. 2001. Development of Sphaerotheca fusca on susceptible, resistant, and temperature-sensitive resistant melon cultivars. Mycol. Res. 105:1216-1222.

25. Poulter, R., Harvey, L., and Burritt, D. J. 2003 Qualitative resistance to powdery mildew in hybrid sweet peas. Euphytica 133:349-358

26. Prats, E., Llamas, M. J., and Rubiales, D. 2007. Characterization of resistance mechanisms to Erysiphe pisi in Medicago truncatula Phytopathology 97:1049-1053.

27. Reuber, T. L., Plotnikova, J. M., Dewdney, J., Rogers, E. E., Wood, W., and Ausubel, F. M. 1998. Correlation of defense gene induction defects with powdery mildew susceptibility in Arabidopsis enhanced disease susceptibility mutants. Plant J. 16:473-485.

28. Röpenack, E. V., Parr, A., and Schulze-Lefer, P. 1998. Structure analyses and dynamics of soluble and cell wall-bound phenolics in a broad spectrum resistance to the powdery mildew fungus in barley. J. Biol. Chem. 273:90139022.

29. Sameshima, T., Kashimoto, K., Kida, K., Matsuda, Y., Nonomura, T., Kakutani, K., Nakata, K., Kusakari, S., and Toyoda, H. 2004. Cytological events in tomato leaves inoculated with conidia of Blumeria graminis $\mathrm{f}$. $\mathrm{sp}$. horde and Oidium neolycopersici KTP-01. J. Gen. Plant Pathol. 70:7-10.

30. Schiffer, R., Görg, R., Jarosch, B., Beckhove, U., Bahrenberg, G., Kogel, K., and SchulzeLefert, P. 1997. Tissue dependence and differential cordycepin sensitivity of race-specific resistance responses in the barley-powdery mildew interaction. Mol. Plant-Microbe Interact. 10:830-839.

31. Sillero, J. C., and Rubiales, D. 2002. Histological characterization of resistance to Uromyces viciae-fabae in faba bean. Phytopathology 92:294-299.

32. Smith, P. H., Foster, E. M., Boyd, L. A., and Brown, J. K. M. 1996. The early development of Erysiphe pisi on Pisum sativum L. Plant Pathol. 45:302-309.

33. Vogel, J., and Somerville, S. 2000. Isolation and characterization of powdery mildew-resistant Arabidopsis mutants. Proc. Natl. Acad. Sci. USA 97:1897-1902.

34. Vorwerk, S., Schiff, C., Santamaria, M., Koh, S., Nishimuta, M., Vogel, J., Somerville, C. and Somerville, S. 2007. EDR2 negatively regulates salicylic acid-based defenses and cell death during powdery mildew infections of Arabidopsis thaliana. BMC Plant Biol. 7:35.

35. Williams-Woodward, J. L., and Daughtrey, M. L. 2001. Hydrangea diseases. Pages 191-194 in: Diseases of Woody Ornamentals and Trees in Nurseries. R. K. Jones and D. M. Benson, eds. American Phytopathological Society, St. Paul, MN.

36. Wurms, K., Labbé, C., Benhamou, N., and Bélanger, R. R. 1999. Effects of milsana and benzothiadiazole on the ultrastructure of powdery mildew haustoria on cucumber. Phytopathology 89:728-736.

37. Zeyen, R. J., Carver, T. L. W., and Lyngkjaer, M. F. 2002. Epidermal cell papillae. Pages 107-125 in: The Powdery Mildews: A Comprehensive Treatise. R. R. Belanger, W. R. Bushnell, A. J. Dik, and T. L.W. Carver, eds. American Phytopathological Society, St Paul, MN. 